\title{
TRIANGULATION, OBJECTIVITY AND THE AMBIGUITY PROBLEM*
}

\author{
MaRTin MONTMiny \\ Philosophy Department \\ University of Ottawa \\ montminy@uottawa.ca
}

\begin{abstract}
SUMMARY: Davidson claims that a creature that has spent its entire life in isolation cannot have thoughts. His two reasons for this claim are that (i) interaction with another creature (what he calls "triangulation") is required to locate the cause of the creature's responses, and that (ii) linguistic communication is necessary to acquire the concept of objective truth, which is itself required in order to have thoughts. I argue that, at best, these two reasons imply that in order to have thoughts a creature must be capable of participating in triangulation, not that it must have already participated in triangulation. I then argue that triangulation doesn't solve the ambiguity problem; that is, it doesn't entail that a being's thoughts and utterances are about distal objects rather than proximal patterns of stimulation. Fortunately, ambiguity, like other forms of indeterminacy, doesn't entail that we cannot have thoughts.
\end{abstract}

KEY WORDS: Davidson, interpretation, reference, norm

RESUMEN: Davidson afirma que una criatura que ha pasado su vida entera aislada no puede tener pensamientos. Aduce dos razones para esto: (i) que se requiere la interacción con otra criatura (lo que él llama "triangulación") para localizar la causa de las respuestas de la criatura, y (ii) que la comunicación lingüística es necesaria para adquirir el concepto de verdad objetiva, que a su vez es necesario para tener pensamientos. Argumento que, en el mejor de los casos, estas dos razones implican que para tener pensamientos una criatura debe ser capaz de participar en una triangulación, no que ya debe haber participado en ella. Arguyo, además, que la triangulación no resuelve el problema de la ambigüedad, esto es, no implica que lo que un ser piensa y dice sea acerca de objetos distantes, más que de patrones de estimulación próximos. Por fortuna, la ambigüedad, como otras formas de indeterminación, no implica que no podamos tener pensamientos.

PALABRAS CLAVE: Davidson, interpretación, referencia, norma

* I am indebted to Ray Elugardo, Sherri Irvin, Maurice Lagueux, Daniel Laurier, Michel Seymour, Robert Sinclair and an anonymous referee for this journal for comments on earlier versions of this paper. I also want to thank the SSHRC for a research grant. 
Consider Robinson Crusoe. Not the one in the novel, but a Robinson who has spent his entire life in isolation. Donald Davidson (1992, p. 266, n. 11) claims that this Robinson doesn't speak a language and doesn't have thoughts. Why? Because if he has never interacted with another person, there could be no fact of the matter about what he is reacting to or thinking about in the world. In this paper, I will consider Davidson's two reasons for this claim. These are based on his notion of triangulation, which is a type of interaction involving two people and a shared environment they are both responding to. According to Davidson, triangulation is necessary to pick out the relevant cause of the two people's respective responses; it is also necessary for the acquisition of the concept of objective truth, which is a necessary condition for being a thinker. I will argue that at best, these two reasons imply that a necessary condition for being a thinker is that one must be capable of participating in triangulation, not that one must already have participated in triangulation. Thus, pace Davidson, a solitary creature could be a thinker. I will then argue that triangulation doesn't allow us to exclude proximal interpretational schemes and thus doesn't solve the problem it is meant to address.

\section{The Solitary Robinson}

According to Davidson, there is nothing in the situation of a solitary person that could establish what he is reacting to in his environment. Let us suppose that every once in a while in the presence of a banana, Robinson says to himself 'banana' or, if you prefer, holds 'This is a banana' true. ${ }^{1}$ When this happens, is he responding to the banana, to patterns of stimulation, or to something else in the causal chain between the banana and the stimulation he undergoes? This question, Davidson tells us, has no answer. Hence, there is what we could call a fundamental

${ }^{1}$ In this paper, I will suppose that Robinson speaks a language phonetically indistinguishable from English, and that his verbal dispositions are those an ordinary English speaker could have. The reader may think it implausible that a solitary person could have acquired such sophisticated dispositions, but none of the theses discussed here depends on the plausibility of this assumption. 
ambiguity $^{2}$ concerning the cause (and content) of Robinson's utterance of 'banana'. There is no fact of the matter about which of the links of the causal chain leading to his utterance counts as the reference of 'banana', since each can be said to cause his utterance:

If we consider a single creature by itself, its responses, no matter how complex, cannot show that it is reacting to, or thinking about, events a certain distance away rather than, say, on its skin. The solipsist's world can be any size; which is to say, from the solipsist's point of view it has no size, it is not a world. (1992, p. 263)

Thus, for Davidson the ambiguity regarding the location of Robinson's responses is serious enough to warrant the claim that he isn't speaking any language or having any thoughts.

This verdict is a bit surprising coming from Davidson, who explicitly endorses Quine's thesis of the inscrutability of reference. ${ }^{3}$ Davidson sees the latter, which is supposed to affect everyone's utterances and thoughts, as showing not that language and thought are impossible, but just that inscrutability is an inescapable part of these phenomena. So why is it the case that indeterminacy between a scheme that interprets 'banana' as meaning banana and one that interprets it as meaning undetached banana part (or temporal stage of a banana) doesn't threaten the possibility of language and thought, whereas the ambiguity concerning Robinson's 'banana' does? There doesn't appear to be any satisfactory answer to this question in the offing.

I should point out, however, Davidson gives two separate reasons why a solitary creature cannot have thoughts:

Society provides two things on which both language and thought depend. The first is the element of objectivity, the awareness of

${ }^{2}$ See Davidson 1999a, p. 13.

${ }^{3}$ See Davidson 1984, essays 15 and 16. Davidson (1999e) continues to endorse the inscrutability thesis. 
the possibility of being wrong. The argument here is that not only is a first language necessarily social, but that thought in general depends on a social check. The second is the determination of the relevant public stimuli which constitute the subject matter of perceptual beliefs. $\left(1999 \mathrm{~b}\right.$, p. 194) ${ }^{4}$

Although my paper will focus mainly on the second element, I will address Davidson's objectivity argument in section 4 .

When we imagine Robinson's situation, it is tempting for us to play the role of "transcendental observers" who can pick out the cause of his responses: we want to say that his utterance of 'banana' refers to a banana, and it is easy for us to point to the banana in our imaginations. But this move is unacceptable, since it imports an external element, a kind of vantage point from which it would be possible to compare Robinson's utterance or thought with what it is supposed to be about; instead of appealing to such external elements, we must show that there is something within Robinson's situation that shows what he is reacting to. According to Davidson, the claim that the banana is the cause of Robinson's response remains arbitrary until Robinson has been involved in triangulation, which is a certain type of interaction with someone who is enough like him.

Before presenting Davidson's account of triangulation, I will consider two objections to his claim about the solitary Robinson. First, someone could protest that Davidson's claim ignores obvious facts about the phenomenology of perception. When we observe our environment, our attention is directed not at, say, our sensory surfaces but at distal objects and events. It seems a plain fact about ourselves that reference is transparent in this way. If the world appears the same way to Robinson as it does to us, then he should be said to respond to bananas and

${ }^{4}$ See also Davidson (1999a, pp. 12-13; 1999c, p. 731; 1999d, pp. 208209), where he clearly distinguishes the two elements that are missing in the solitary creature's situation: something that can give substance to the distinction between correct and incorrect responses, on the one hand, and a way of deciding whether the relevant stimulus is distal or proximal, or somewhere in between, on the other hand. 
not to patterns of stimulation. Unfortunately, facts about how the world appears to us are of no help in establishing what the objects of our attention are. This point can be easily appreciated when one takes note of the fact that Robinson's twin-brain-ina-vat shares Robinson's phenomenology: since the world might be very different from how Robinson takes it to be, and yet appear to him just the way it currently does, considerations about his phenomenology aren't sufficient to single out distal stimuli as the objects of his thoughts. One could perhaps object that Robinson's phenomenology cannot be the same as that of his twin-brain-in-a-vat, since phenomenological facts should be construed broadly, that is, as essentially involving relations with his environment. Unfortunately, this objection just brings us back to our initial problem: What makes it the case that the objects and events in relation to which Robinson's phenomenology is to be construed are distal and not proximal?

It should be clear that no question is begged against externalism here. Consider for instance Burge's perceptual externalism (1986), according to which the content of a subject's perceptual experience is determined (at least partly) by what normally causes it. What has been said so far doesn't deny that this is true of Robinson. In fact, in this paper, I am taking for granted that the meaning of an observational sentence like 'This is a banana' is closely related to what normally causes speakers to hold that sentence true. So, the content of the experience of a twin of Robinson who lives in a different environment will differ from the content of Robinson's experience if the causes of their respective experiences are not the same. The issue thus comes down to providing a general account of how to isolate these causes.

There is perhaps a way to substantiate the first objection to Davidson based on the phenomenology of perception by appealing to the phenomenon of perceptual constancy. Our experiences of a given object can remain unchanged in response to quite different proximal stimulations, when we vary the conditions (illumination, orientation, distance, etc.) under which the object is presented. For example, when an object moves 
toward or away from us, we don't have the impression that its size changes, though the retinal image projected by the object either grows or diminishes. Hence, the objection to Davidson would go, the existence of perceptual constancy shows that our experience represents not the proximal events on which it causally depends, but distal objects in this causal chain. ${ }^{5}$ Some experimental results suggest that perceptual constancy is already present at birth, and it is not unreasonable to think that it is based on innate neurological mechanisms. ${ }^{6}$ Perceptual constancy would thus also be true of Robinson, and this would show that his responses are actually directed at bananas and not at proximal stimuli. One could also point out that Robinson has more than one way of identifying a banana: he can visually perceive it, but he can also recognize its smell and detect it by touching or tasting it. Hence, there are several routes that go from the banana to Robinson's response, and these routes intersect at only two points: the banana and Robinson's response.

Unfortunately, these considerations don't show that Robinson is not reacting to a proximal stimulus. The fact that the same distal object can give rise to quite different proximal stimulations doesn't exclude the possibility that the cause of Robinson's response is a disjunctive proximal stimulus. Let us define the stimulus-cause of Robinson's sentence 'This is a banana' as the class of stimulations of any of his sensory modalities that would prompt him to hold this sentence true. This notion of stimulus-cause is adapted from Quine's notion of stimulusmeaning (1960, chap. 2); although on the present approach, a stimulation is not a pattern of triggered sensory receptors, but a pattern of irradiation that triggers these receptors; it is thus external to the subject.

Saying that the cause of Robinson's response is a stimulation belonging to the stimulus-cause of his sentence 'This is a banana' is entirely compatible with perceptual constancy and with

${ }^{5}$ See Dretske (1981, chap. 6) for an argument of this type.

${ }^{6}$ Many cognitive psychologists would add that we come innately equipped with a certain conception of ordinary physical objects. See Mehler and Dupoux (1994, chap. 3) for a useful overview. 
the fact that Robinson can identify bananas by means of various sensory modalities. A wide diversity of stimulations will prompt Robinson's utterances of 'This is a banana', but these all belong to the stimulus-cause of that sentence. Hence it may be true that Robinson naturally classes bananas together, but when he does so, he is at the same time grouping together stimulations in the class of the stimulus-cause of 'This is a banana'. So what makes bananas the right choice as the cause of his utterances of 'This is a banana'? Actually, as Davidson (1992, p. 262) points out, if what we want is to isolate the cause of Robinson's utterance (as opposed to its content), it seems that the stimulus-cause would be a better candidate, since stimulations belonging to the stimulus-cause of his 'This is a banana' more reliably bring about the response than bananas. ${ }^{7}$

\section{Robinson Meets Friday}

In order to locate the cause of Robinson's responses to his environment, Davidson argues, there has to be a second person interacting with him in a certain way. He describes this interaction as a triangulation: one line goes from Robinson to the banana, one line goes from the interpreter, say, Friday, to that same banana, and a third line goes from Friday to Robinson. More is required of course. Davidson points out that three similarity patterns must be present: Robinson finds bananas similar (to each other); Friday finds bananas similar (to each other); and Friday finds Robinson's responses in the presence of bananas similar (to each other). If all of this is true of Robinson and Friday, the latter is in a position to establish that the common cause of their respective reactions is a banana, since such a banana is the object that is located at the intersection of the two lines that we could draw from each of the participants.

I should point out that, for Davidson, triangulation is not supposed to eliminate all forms of inscrutability of reference. It is meant to resolve the ambiguity of the relevant stimulus, that is, the question of whether the stimulus of a speaker's

${ }^{7}$ The same remark may not apply if we are interested in the content of Robinson's utterance. I will come back to this issue in section 5 . 
response is proximal or distal: "What makes the distal stimulus the relevant determiner of content is again its social character; it is the cause that is intersubjectively shared" (Davidson 1999a, p. 13). Clearly, the fact that the cause of Robinson's utterance of 'This is a banana' is distal doesn't exclude the possibility that his word 'banana' refers to undetached banana parts, for example. In what follows, I will ignore cases of indeterminacy among distal stimuli and focus on the indeterminacy between distal and proximal stimuli. To avoid confusion, I will call the latter the problem of the ambiguity of the relevant stimulus or, more succinctly, the ambiguity problem. To repeat, Davidson claims that triangulation solves the ambiguity problem, and this is the claim that I want to challenge.

Now surely, Davidson isn't claiming that thoughts can occur in a person only when that person is interacting with an interpreter; his point is not that thought and language require that one is currently communicating with someone else. Still, one may wonder what makes it the case that I can have thoughts when I am temporarily isolated, or when people around me are not reacting to the same objects I am focusing on.

Perhaps Davidson could say, following John Heil's suggestion (1992, p. 219), that it is the availability of interpreters that is required for thoughts. On this view, what allows me to have beliefs about bananas when I'm alone is that there are interpreters who are available to interpret my language. But this suggestion is not satisfactory for a number of reasons. First, it is not clear how we should apply the notion of availability in this context. There is a sense in which we are available as interpreters to the solitary Robinson. After all, we (or Friday) could drop in on his island at any time. But clearly Davidson would reject the claim that because of this possibility, it is correct to say that Robinson has thoughts. Second, consider the Robinson of Dafoe's novel, when he is temporarily isolated after the shipwreck and before he meets Friday. Does he have thoughts? It seems that Davidson would say 'yes'. ${ }^{8}$ But on any construal of 'availability', interpreters are not more available for him than they are

${ }^{8}$ See for instance Davidson (1992, p. 266, n. 11). 
for "our" Robinson. Finally, consider the case of Swampman (Davidson 1987), who is a physical replica of Davidson that was just created as a result of lightning striking a dead tree. Davidson claims that though Swampman has sophisticated verbal (and nonverbal) dispositions, he is neither a speaker of a language nor a thinker. This is because, he continues, Swampman lacks the proper history of causal interaction with the world. At no point does the availability of interpreters seem to be a relevant factor for Davidson in determining whether Swampman has thoughts. It is thus not compatible with Davidson's view to claim that what enables temporarily isolated speakers to have thoughts is the availability of interpreters.

A more promising proposal is that it is because I have been involved in triangulation before that I can have thoughts when I'm alone. My past interactions with other people have fixed the contents of many of my thoughts, or have at least established that my 'basic' or 'observational' thoughts are about distal objects and events in the environment rather than about the stimulations I undergo when I observe these objects and events. Of course, this doesn't guarantee that I have thoughts when I am by myself. After all, I could have lost all capacities for thought at some point. An additional condition is thus that I still have the capacity to participate in triangulation with another person. Thus, on this view, person $S$ has thought only if $S$ has participated and can still participate in triangulation. I will call this the strong community view, and will contrast it with the moderate community view, ${ }^{9}$ which asserts that in order to have thoughts, a creature must be capable of participating in triangulation. One of my goals in this paper is to show that Davidson's arguments for the strong community view fails.

Here's the plan for the rest of the paper. In sections 3 and 4 , I will discuss Davidson's two reasons in favor of the strong community view; I will argue that, at best, they support the

${ }^{9} \mathrm{I}$ should point out that the moderate community view is compatible with the claim that Swampman is not a thinker: perhaps an additional necessary condition for thought is a history of interaction with an environment. I will not try to settle this issue here. 
moderate community view. Then, in section 5 , I will show that Davidson's triangulation does not solve the ambiguity problem. My conclusion will be that the ambiguity of the relevant stimulus is no more problematic than other forms of indeterminacy such as the inscrutability of reference.

\section{The Common Cause}

Let's consider again the question of the location of the stimulus of Robinson's response. In some passages, Davidson seems to suggest that what makes it the case that Robinson's responses are to bananas is that Friday (or the interpreter) finds it natural to group bananas together as the causes of Robinson's various utterances of 'banana'. But this suggestion cannot work, for reasons that were given earlier in the case of the solitary Robinson. We cannot take for granted that the stimuli that Friday finds it natural to group together are bananas and not patterns of stimulation he himself undergoes. The initial problem was of motivating the claim that Robinson's utterance is about a banana and not about patterns of stimulation. The current suggestion merely replaces this problem with another one, namely that of showing that what Friday (the interpreter) finds it natural to group together are bananas and not patterns of stimulation.

In fact, the crucial aspect of triangulation is that it introduces a common cause of Robinson's and Friday's responses. Friday can observe that what caused Robinson's response is the same object that caused his (similar) response. Hence, Robinson's utterance of 'banana' is about a banana and not about the stimulations he undergoes, since the former, but not the latter, can be said to cause Friday's own response. Compare the situation of the solitary Robinson: in this case, both the banana and the stimulations he undergoes can be said to cause his utterance of 'banana', which is the only response that is being produced. Introducing a second person can thus set apart the causal roles of the banana and the patterns of stimulation, in terms of the responses they respectively produce: only the former causes both speakers' responses. 
However, it is not clear why there needs to be (or to have been) an actual interaction with a second person in order to determine the cause of Robinson's response. Why not say that the solitary Robinson's utterance of 'banana' is (in typical cases) caused by a banana, since an appropriately informed interpreter could establish this, if such an interpreter were to interact with him? In other words, why not say that the possibility of triangulation with a person enough like him is sufficient to determine what the solitary Robinson is reacting to? On this suggestion, considerations about common causes would support only the moderate version of the community view which, recall, states only that thought requires the capacity to participate in triangulation. Perhaps Davidson could reply that the fact that an appropriate type of interaction with Friday in some counterfactual situation would establish that Robinson is, in that counterfactual situation, responding to bananas and not to patterns of stimulation, doesn't entail that the solitary Robinson is, in the actual situation, responding to bananas and not to patterns of stimulation. But I don't see why we should accept this reply.

Consider the following two situations. In Situation A, the solitary Robinson is looking at a banana and utters 'banana'. This occurs before Robinson first meets Friday. Situation B is just like Situation A, except that it takes place after Robinson has interacted with Friday. According to the strong community view, it is only in Situation B that Robinson's utterance can be said to be about a banana and not about patterns of stimulation. This is not because interaction with a second person is necessary to "instill" into Robinson a new perspective on his environment that makes him focus on distal objects as opposed to proximal ones. Davidson's point regarding triangulation is not that it is required for the participants to undergo some psychological processes that result in their learning where the causes of their various responses are located. Thus, the only difference between Situation A and Situation B has to do with Robinson's history. But I don't see why the mere fact that Robinson has interacted with Friday makes it the case that he is responding to distal 
stimuli, whereas no such thing can be said about an identical situation occurring before he has met Friday. Davidson's claim that only actual interaction with Friday can rule out a proximal interpretation of his utterance is unmotivated.

\section{The Objectivity Argument}

Let us now turn to Davidson's second reason in favor of the strong community view, what I have called his 'objectivity argument'. This argument proceeds in two steps:

(I) In order to have beliefs, one must possess the concepts of belief and objective truth;

(II) Linguistic communication with others is necessary for acquisition of the concepts of belief and objective truth.

If we grant Davidson's claim that "without belief there are no other propositional attitudes" (1985, p. 478), then (I) and (II) entail the strong community view. Actually, (I) and (II) entail an even stronger thesis, namely the view that one must have engaged in linguistic interaction with another being in order to have thoughts. Unlike the strong community view, this view entails that only linguistic creatures can have thoughts.

Davidson's defense of $(\mathrm{I})^{10}$ starts with the idea that one cannot have beliefs unless one can understand their propositional content. This idea, combined with the claim that "in order to understand a proposition one must know what its truth conditions are" (1995, p. 211), entails that a creature has beliefs only if it understands that they can be true or false. And since such an understanding requires the possession of the concepts of belief and objective truth, only creatures that have these concepts can have beliefs, as (I) claims. I should add that, for Davidson, one possesses the concept of belief just in case one possesses the concept of objective truth, since "to have the concept of truth is to have the concept of objectivity, the notion of a proposition

${ }^{10}$ Davidson's argument for (I) is best explained in 1995, pp. 207-211, but see also his 1984, p. 170; 1985, pp. 479-480; 1999a, pp. 12-13; 2001, p. 126. 
being true or false independent of one's beliefs or interests" (1995, p. 211), and "the concept of belief [...] is the concept of a state of an organism which can be true or false" (1985, p. 479).

Davidson's argument for (II) invokes triangulation. ${ }^{11}$ The latter, he writes, is required to "create the space" for error and to allow for the acquisition of the concept of objective truth. A creature that has not compared its responses to those of another creature cannot distinguish between what seems to be the case and what is the case. Nothing, in the situation of an isolated creature, enables us to draw the distinction between an adequate response to the environment and an inadequate one. Therefore, such a being cannot possess the concept of objective truth. According to Davidson, interaction with others is necessary to allow for the distinction between getting it right and getting it wrong. The presence of another individual who observes the same environment allows for a comparison between two responses that may or may not diverge. Thus, a community of at least two individuals is required for the introduction of a norm that makes it possible to acquire (and apply) the concept of objective truth. Now such an interaction must be linguistic, he adds, since language is the only way to communicate one's propositional contents to another being.

Many commentators have challenged Davidson's argument for (I), invoking animals and young children as counterexamples. Davidson's standards for belief, it is said, are much too demanding. A similar, but weaker and more plausible, condition would be that a creature can be credited with beliefs only if it is disposed to adjust its representations appropriately to changes in the environment. ${ }^{12}$ In other words, the creature's sensitivity to the norms of correctness would consist not in its understanding that its beliefs may be right or wrong, but in its disposition to change its beliefs appropriately when confronted with new perceptual evidence. Since one can have this disposi-

${ }^{11}$ See for instance Davidson 1984, p. 170; 1985, pp. 479-480; 1991a, p. 201; 1992, pp. 264-265; 1999a, pp. 13-14; 2001, pp. 126-127.

${ }^{12}$ See for instance Smith 1982, p. 507. 
tion without having the concepts of belief and objective truth, this weaker condition would not support (I).

Davidson (1985, p. 479) puts forward an alternative argument for (I). He argues that (i) having a belief entails the possibility of surprise, and that (ii) surprise involves a belief about the correctness of one's beliefs, since it requires the awareness of a contrast between a prior belief and a current one. But this argument is subject to a similar objection. One could grant (i) but deny (ii), that is, deny that a creature has the capacity for surprise only if it is capable of having the belief that one of its own beliefs fails to be true. In other words, one could adopt a less intellectualized notion of surprise that merely involves a change of belief accompanied by startle. ${ }^{13}$ Only on this interpretation of 'surprise' does it appear plausible that the capacity for surprise is a necessary condition for belief, as (i) claims. So Davidson cannot plausibly hold (i) and (ii) simultaneously.

Davidson's argument for (II) can also be challenged. It seems that a solitary creature is in as good a position to acquire the concept of objective truth as are the participants in triangulation. There are at least three ways in which it can come to understand that one of its beliefs is wrong. First, a solitary creature can compare its current reaction to a past one. ${ }^{14}$ Robinson observes a bent stick that is half immersed in water. His impression is that the stick is curved. But later on, he observes the same stick from a different angle, and it now seems straight. This pair of observations can enable Robinson to realize that what seems to be the case may be different from what is the case, since at least one of his two impressions must be wrong. A second method available to the solitary creature is to try to see if its current reaction satisfies a generalization it has so far admitted. Since every time he throws a stone in the pond, it sinks, Robinson expects the stone he is about to throw to sink as well. But today the pond is frozen and, to Robinson's surprise, the stone rebounds on the water's surface. This observation goes

${ }^{13}$ See DeGrazia (1996, p. 149), Glock (2000, pp. 55-56) and Beisecker (2002, p. 118) for similar suggestions.

${ }^{14}$ See Heil (1992, p. 217) for a similar suggestion. 
against Robinson's previously held generalization according to which every stone thrown in the pond sinks and can thus allow him to distinguish between his expectations and what actually happens. Thirdly, the solitary creature can compare its actual reaction to one it would have if it observed the same situation from a different perspective. It can indeed imagine how things would appear if its distance or angle were different, if lighting conditions were not the same, etc. The horse that Robinson sees in the distance seems to have three legs. But he can imagine how this horse would appear if his viewpoint were different; maybe it would seem to have four legs. Such a "thought experiment" can enable Robinson to realize that there may be some discrepancies between the way things are and the way they appear to him.

It's important to note that in order to possess the concept of objective truth, a creature doesn't need to be able to demonstrate what reality is like independently of its beliefs. So, for instance, it doesn't need to occupy a position outside its own mind or to compare its beliefs with what it takes them to be about. What possessing the concept of objective truth requires is an understanding that the truth or falsity of a proposition is independent of one's believing this proposition. And, as I just suggested, there are at least three ways a solitary creature can come to such an understanding.

Davidson often writes that only a community of speakers can make possible the distinction between getting things right and getting them wrong. Thus, the existence of a community would be necessary for the concept of objective truth to be applicable. This is because, Davidson writes, invoking Wittgenstein, "following the rule (getting things right) is at bottom a matter of doing as others do" (1999a, p. 13). ${ }^{15}$ The suggestion is that it does not make sense to say that a person got things right (or wrong) unless we compare her responses to someone else's.

Unfortunately, what this argument shows, at best, is that a comparison between the responses of two different speakers

${ }^{15}$ Note that this argument is slightly different from the one based on (I) and (II), since it concerns not the acquisition of the concept of truth but its applicability. 
must be possible for a norm of correctness to be applicable, not that such a comparison must actually have been made. Perhaps the concept of objective truth can be applied to Robinson's response only if this response is judged according to our norms of correctness. But this doesn't mean that we have to be interacting with Robinson to say that his response is right or wrong; all that this requires is the possibility of comparing his response to ours. Hence, the argument supports not the strong community view, but its moderate version. An analogy with color concepts is useful here. Being red is at bottom a matter of being judged red by normal observers. One may plausibly hold that the concept of red is applicable to a surface only if a normal observer would judge it to be red (under certain circumstances). But the fact that the redness of a surface depends essentially on the judgments of a normal observer doesn't entail that a surface must actually have been observed in order to be red. Why should things be different with the concept of objective truth? Davidson's brief remarks don't show why linguistic communication must have occurred for such a concept to be applicable.

\section{The Ambiguity Problem}

I have argued that Davidson's two reasons for the strong community view are unsatisfactory. I now propose to examine the question of whether triangulation can solve the ambiguity problem. Does triangulation entail, as Davidson claims, that our thoughts and utterances are not about patterns of stimulation?

In section 3, I pointed out that the crucial aspect of triangulation is the notion of common cause: unlike the stimulation that causes Robinson's response or the one that causes Friday's response, the banana can be said to be causally responsible for both Robinson's and Friday's responses. The problem, though, is that the participants in triangulation are not in a position to refer unambiguously to this common cause. As transcendental observers of Robinson and Friday's situation, we can pick out the object that causes both of their reactions, but these speakers 
cannot adopt such a perspective on their situation. Words just don't latch on to objects in some pre-programmed way. So what could be the mechanism that connects Robinson's word 'banana' with bananas? Friday's and Robinson's talking (or thinking) about the 'common cause' of their reactions will not suffice. Suppose that Robinson utters, 'Friday and I are both reacting to a common cause'. What makes it the case that 'common cause' in this utterance designates the banana as opposed to a stimulation resulting from the banana? Robinson's expression 'the common cause' is as much in need of an interpretation as his word 'banana'. Under the proximal interpretation Robinson can still think or talk about 'the common cause of Friday's reaction and mine', but his expression 'the common cause' designates not a distal object but a stimulation belonging to the stimuluscause of 'This is a banana'. Nothing in Robinson's claims and attitudes (i.e., which sentences he holds true) invalidates this interpretation.

One way to appreciate this point is to go back to the situation of the solitary Robinson. Suppose he witnesses the following scene: a banana collides with an orange. Clearly, it is not Robinson's stimulation but the banana that hits the orange. Thus, the stimulation and the banana don't have the same causal roles: the latter can causally interact with objects in the environment in a way that the former cannot. But this doesn't entail that Robinson's utterance of 'The banana collided with the orange' is about a banana colliding with an orange and not about patterns of stimulation resulting from that distal event. Insisting that Robinson's word 'banana' uniquely refers to the thing that both causes his utterance and collides with the orange presupposes a transcendental perspective from which we can select the thing in question. Similarly, in the triangulation case, the claim that Robinson's word 'banana' has a distal reference, since it is about the thing that causes both his and Friday's responses, implicitly appeals to a transcendental observer. Such an observer can certainly pick out the banana, the common cause of the speakers' reactions, but to rule out the proximal scheme, one must appeal only to features of the speakers' situation. My 
point is that these are not sufficient to pick out a distal object as opposed to a proximal one.

It should be noted that this point is independent of considerations about objectivity and norms of correct use. We can assume that the participants in triangulation possess the concept of objective truth and that the correctness conditions of their sentences are fixed. It is indeed possible to construct a proximal scheme that assigns truth conditions that are equivalent to those of the distal scheme. On such a scheme, 'banana' refers to stimulations originating from a banana (or, SOB's for short). An SOB is, by definition, a stimulation that could in principle affect one of our sensory modalities and that a banana is disposed to produce. On this definition, a stimulation not produced by a banana cannot be an SOB, even if it is indistinguishable in its intrinsic properties from an SOB. An SOB must thus originate from a banana. Therefore, when there is an SOB, there is also a banana. On the other hand, I take it that all bananas are disposed to produce stimulations that could in principle affect us. A banana behind a wall or inside a block of concrete isn't producing stimulations that currently affect us; however, it is disposed to produce stimulations that would have an effect on us. Real bananas have causal powers, and the causal effects produced by a banana can be amplified to become stimulations that our sensory modalities are sensitive to. So in every possible situation in which there is a banana, there is also an SOB. Since there is an SOB just in case there is a banana, the distal and the proximal schemes will make Robinson's sentence 'There is a banana' correct and incorrect in exactly the same circumstances. ${ }^{16}$

${ }^{16}$ Note that this would not be true of a proximal scheme based on the stimulus-cause of 'There is a banana'. There are situations in which a banana is present but, because of dim illumination or unusual orientation, Robinson would not hold 'There's a banana' true. Alternatively, some fake bananas would cause Robinson to hold 'There's a banana' true. Therefore, interpreting Robinson as meaning banana by 'banana' would make him wrong more often than interpreting him as meaning stimulation belonging to the stimulus-cause of 'There's a banana'. Actually, on the latter interpretation, Robinson would be right all the time. 
Some may object that if we considered more complex sentential constructions in which 'banana' appears as a constituent, our assessment of the proximal scheme would likely change. ${ }^{17}$ For instance, the fact that Robinson would hold 'This banana is ripe' true in the presence of a ripe banana seems to contradict the view that Robinson's 'banana' means $S O B$, since it doesn't make sense to claim that an SOB is ripe. But the problem with this objection is that it presupposes that Robinson's predicate 'is ripe' has a determinate interpretation, and means is ripe. But the proponent of the proximal scheme could very well interpret 'is ripe' as meaning is a stimulation originating from a ripe thing. And since a banana is ripe just in case a stimulation originating from it is a stimulation originating from a ripe thing, the proximal scheme can account for Robinson's utterance of 'This banana is ripe' just as well as the distal scheme. Other sentences involving 'banana' can be accommodated similarly by the proponent of the proximal scheme. ${ }^{18}$ In other words, it is possible to systematically modify the satisfaction relations in such a way that the proximal scheme yields truth conditions that are equivalent to those of the distal scheme.

But perhaps an adequate interpretation must satisfy stronger constraints. Consider for instance Davidson's principle of correspondence, a version of the principle of charity that "prompts the interpreter to take the speaker to be responding to the same features of the world that he (the interpreter) would be responding to under similar circumstances" (1991b, p. 158). This principle entails that since, in typical cases, our thoughts and utterances are about distal objects and events and not about stimulations, we should interpret Robinson as responding to distal objects and events as well (if we participate in triangulation with him). ${ }^{19}$ This approach is in line with Davidson's account

${ }^{17}$ See Evans (1975) and Brandom (1994, pp. 409-412) for such an objection. Some of my responses to the objections to the proximal scheme are inspired by Quine's classical discussions of the inscrutability thesis (1960; 1969).

${ }^{18}$ For instance, 'Friday is responding to this banana' would be interpreted as meaning the stimulation originating from Friday is originating from a thing that is responding to a thing that this $S O B$ is originating from.

${ }^{19}$ See Horwich (1998, chap. 9) for a similar suggestion. 
of triangulation, in which the speakers take each other to be responding to the same (distal) cause. Applying the principle of correspondence would clearly exclude the proximal scheme: we would interpret Robinson as responding, like us, to bananas and not to SOB's. One may insist that this principle is so central to interpretation that without it we would be performing a different activity. In other words, we take ourselves to be responding to distal objects in the environment, and it would never occur to us (in typical circumstances) to interpret someone else as speaking about stimulations instead of these distal objects. We would consider a proponent of the proximal scheme to be involved in an activity that has little to do with interpretation and understanding of others. This scheme should thus be rejected, since it doesn't conform with our ordinary practice. A somewhat related reason to discard the proximal scheme would be to invoke pragmatic constraints on interpretation. One could claim for instance that the proximal scheme is unduly complicated and would not survive the application of a methodological criterion of simplicity.

Unfortunately, this objection can work only if we presuppose that our own words have determinate references. But, this is the presupposition that is currently being challenged. So what the present approach can do at best is provide a determinate mapping of Robinson's words into ours. But it cannot exclude the possibility that Robinson's word 'banana' refers to SOB's, if such a possibility cannot be excluded with respect to our word 'banana'. Similarly, considerations about the naturalness and simplicity of interpretational schemes could perhaps rule out the proximal scheme, but they would not establish that Robinson's word 'banana' doesn't refer to SOB's: in order to establish this, we would need to show that our word 'banana' doesn't refer to SOB's.

One may object that construing ordinary speakers as normally thinking and talking about SOB's produces implausible psychological attributions and explanations. ${ }^{20}$ It seems that

${ }^{20}$ See Hookway (1988, chap. 9) and Wright (1997) for a similar objection to the inscrutability thesis. 
a psychological state or process involving the concept of SOB is more complex than one involving the concept of banana. One may add that a subject could not grasp the concept of SOB without having the concept of banana, since the latter is contained in the former. Interpreting a speaker's basic thoughts as being about stimulations originating from objects, as the proximal scheme does, overlooks this fact.

This objection misses the point, though. The proximal scheme doesn't assign a more complex or twisted psychology than the distal one. Having a word that means $S O B$ according to the proximal scheme is no more work than having a word that means banana according to the distal scheme. Actually, it amounts to exactly the same thing! The two referential schemes are compatible with exactly the same set of dispositions to hold sentences true in response to features of the environment and the same network of interconnections among these sentences.

This is true even if these sentences are in a Language of Thought. Appealing to Robinson's mental symbols instead of his words won't narrow down the interpretational options: everything I have said about the adequacy of the proximal scheme regarding Robinson's word 'banana' also applies to the Language of Thought equivalent of this word. In no way is the alternative scheme committed to more complex Language of Thought equivalents than the distal scheme is. Thus, grasping a concept that means $S O B$ is a more complex psychological process than grasping a concept that means banana, and having the former concept requires having the latter, only if we assume a scheme according to which primitive mental symbols refer not to proximal objects but to distal ones. But this is the assumption that is being called into question.

\section{Conclusion}

I have argued that the two reasons Davidson offers in support of the strong community view are unsatisfactory. His claim that triangulation is necessary both for solving the ambiguity problem and for providing the norms of correct use at best supports the moderate community view. I have argued, further, that tri- 
angulation doesn't solve the ambiguity problem. So where does this leave us? Considerations about the ambiguity problem are irrelevant to determining whether the strong community view (or the moderate community view for that matter) is correct or not. This is because this problem, I have argued, does not have a solution. So the fact that the strong (or moderate) community view fails to provide a solution to the ambiguity problem should not count against it. But my discussion of the two versions of the objectivity argument draws different conclusions. First, Davidson's arguments for the theses that having beliefs requires possessing the concept of objective truth, and that triangulation is necessary for the acquisition of this concept, are unconvincing: his standards for belief are implausibly high, and, furthermore, it's not the case that participating in triangulation is required to satisfy them. However, I have contended that Davidson's argument based on Wittgenstein's insight that a community is needed for the concept of objective truth to be applicable entails not the strong community view, but the moderate one. I thus conclude that Davidson's two reasons in favor of the strong community view at best support the moderate version of this view. To have thoughts, a creature need not have participated in triangulation, but only have the capacity to participate in triangulation.

The insolubility of the ambiguity problem should not lead us to conclude that we don't have thoughts. Ambiguity, just like other forms of indeterminacy, is something we have to live with. It should be noted that ambiguity doesn't entail that we don't know what we are talking or thinking about. There is clearly a sense in which we know what 'banana' refers to: it refers to bananas, and nothing I have said here contradicts this. To see why, let us consider again our two interpretations of Robinson: both schemes would interpret his utterance " 'banana' refers to bananas" as true. Instead of interpreting it homophonically, the proximal scheme would interpret Robinson as saying that his word 'banana' refers to SOB's, which, of course, is true according to the interpretation it proposes of Robinson's word 'banana'. These considerations can also apply to our own claims 
about what our words mean and refer to: if they are true under the distal scheme, then they remain true under the proximal one. Unfortunately, the truth of our claims about what our words refer to doesn't establish determinate word-world relationships.

\section{REFERENCES}

Beisecker, David, 2002, "Some More Thoughts About Thought and Talk: Davidson and Fellows on Animal Belief", Philosophy, vol. 77, pp. 115-124.

Brandom, Robert, 1994, Making It Explicit, Harvard University Press, Cambridge (Mass.).

Burge, Tyler, 1986, "Cartesian Error and the Objectivity of Perception", in P. Pettit and J. McDowell (eds.), Subject, Thought, and Context, Oxford University Press, Oxford, pp. 117-136.

Davidson, Donald, 2001, "What Thought Requires", in J. Branquinho (ed.), The Foundations of Cognitive Science, Clarendon Press, Oxford, pp. 121-132.

-, 1999a, "The Emergence of Thought", Erkenntnis, vol. 51, pp. 7-17. 194.

- 1999c, "Reply to Dagfinn Føllesdal", in L.E. Hahn 1999, pp. 729-732.

—_ 1999d, "Reply to Thomas Nagel", in Hahn 1999, pp. 207-209.

—, 1999e, "Reply to W.V. Quine", in L.E. Hahn 1999, pp. 80-85.

- 1995, "The Problem of Objectivity", Tijdschrift Voor Filosofie, vol. 57, pp. 203-220.

, 1994, "The Social Aspect of Language", in B. McGuinness and G. Oliveri (eds.), The Philosophy of Michael Dummett, Kluwer Academic Publishers, Dordrecht, pp. 1-16.

1992, "The Second Person", in A.P. French, T.E. Uehling and H. Wettstein (eds.), Midwest Studies in Philosophy, vol. 17, University of Notre Dame Press, Notre Dame, pp. 255-267.

_ , 1991a, "Epistemology Externalized", Dialectica, vol. 45, pp. 191-202.

- 1991b, "Three Varieties of Knowledge", in A. Phillips Griffiths (ed.), A.J. Ayer: Memorial Essays, Cambridge University Press, Cambridge, pp. 153-166. 
Davidson, Donald, 1990, "The Structure and Content of Truth", Journal of Philosophy, vol. 87, pp. 279-328.

1987, "Knowing One's Own Mind", Proceedings and Addresses of the American Philosophical Association, vol. 60, pp. 441458.

, 1985, "Rational Animals", in E. Lepore and B. McLaughlin (eds.), Truth and Interpretation: Perspectives on the Philosophy of Donald Davidson, Basil Blackwell, Oxford, pp. 473-481.

- , 1984, Inquiries into Truth and Interpretation, Clarendon Press, Oxford.

DeGrazia, David, 1996, Taking Animals Seriously, Cambridge University Press, Cambridge.

Dretske, Fred, 1981, Knowledge and the Flow of Information, MIT Press, Cambridge (Mass.).

Evans, Gareth, 1975, "Identity and Predication", Journal of Philosophy, vol. 72, pp. 343-363.

Glock, Hans-Johann, 2000, "Animals, Thoughts and Concepts", Synthese, vol. 123, pp. 35-64.

Hahn, L.E. (ed.), 1999, The Philosophy of Donald Davidson, Open Court, Chicago and La Salle (Ill.).

Heil, John, 1992, The Nature of True Minds, Cambridge University Press, Cambridge.

Hookway, Christopher, 1988, Quine, Stanford University Press, Stanford.

Horwich, Paul, 1998, Meaning, Clarendon Press, Oxford.

Mehler, Jacques and Emmanuel Dupoux, 1994, What Infants Know, Basil Blackwell, Cambridge (Mass.).

Quine, W.V.O., 1969, "Ontological Relativity", Ontological Relativity and Other Essays, Columbia University Press, New York, pp. 26-68.

$\longrightarrow, 1960$, Word and Object, MIT Press, Cambridge (Mass.).

Smith, Peter, 1982, "On Animal Beliefs", Southern Journal of Philosophy, vol. 20, pp. 503-512.

Wright, Crispin, 1997, "The Indeterminacy of Translation", in B. Hale and C. Wright (eds.), A Companion to the Philosophy of Language, Oxford, Blackwell, pp. 397-426.

Received March 24, 2003; revised January 5, 2004; accepted February 4, 2004 . 